Edith Cowan University

Research Online

ECU Publications 2011

2011

Synthesis of high-performance magnetic garnet materials and garnet-bismuth oxide nanocomposites using physical vapor deposition followed by high-temperature crystallization

\author{
Mohammad Nur E Alam \\ Edith Cowan University \\ Mikhail Vasiliev \\ Edith Cowan University \\ Kamal Alameh \\ Edith Cowan University \\ Viacheslav Kotov
}

Follow this and additional works at: https://ro.ecu.edu.au/ecuworks2011

Part of the Physical Sciences and Mathematics Commons

10.1351/PAC-CON-11-02-02

This is an Author's Accepted Manuscript of: Nur E Alam, M. , Vasiliev, M. , Alameh, K. , \& Kotov, V. (2011). Synthesis of high-performance magnetic garnet materials and garnet-bismuth oxide nanocomposites using physical vapor deposition followed by high-temperature crystallization. Pure and Applied Chemistry, 83(11), 1971-1980. Available here

This Journal Article is posted at Research Online.

https://ro.ecu.edu.au/ecuworks2011/171 
Pure Appl. Chem., Vol. 83, No. 11, pp. 1971-1980, 2011.

doi:10.1351/PAC-CON-11-02-02

(C) 2011 IUPAC, Publication date (Web): 7 July 2011

\title{
Synthesis of high-performance magnetic garnet materials and garnet-bismuth oxide nanocomposites using physical vapor deposition followed by high-temperature crystallization*
}

\author{
Mohammad Nur-E-Alam ${ }^{1, \ddagger}$, Mikhail Vasiliev ${ }^{1}$, Kamal Alameh ${ }^{1,2, \ddagger}$, and \\ Viacheslav Kotov ${ }^{3}$ \\ ${ }^{1}$ Electron Science Research Institute, Edith Cowan University, 270 Joondalup Dr., \\ Joondalup, WA 6027, Australia; ${ }^{2}$ Department of Nanobio Materials and Electronics, \\ Gwangju Institute of Science and Technology, Korea; ${ }^{3}$ Institute of Radio \\ Engineering and Electronics, Russian Academy of Sciences, 11 Mohovaya St., \\ Moscow 125009, Russia
}

\begin{abstract}
Bi-substituted iron garnet (Bi:IG) compounds synthesized in thin film form are the best semi-transparent magneto-optical (MO) materials for applications in magnetic recording, optical sensors, and photonics. These materials can possess attractive magnetic properties and the highest specific Faraday rotation in the visible and near-infrared spectral regions, if the deposited layers contain a high volumetric fraction of the garnet phase and possess high-quality surfaces and microstructure. In this paper, we study the effects of various deposition and annealing process parameters on the properties of $\mathrm{Bi}: \mathrm{IG}$ and garnet-oxide nanocomposite films of several composition types fabricated using radio-frequency (RF) sputtering deposition followed by high-temperature isothermal crystallization. We also investigate the kinetics of garnet phase formation within a garnet-Bi-oxide nanocomposite material.
\end{abstract}

Keywords: chemical physics; magnetochemistry; magnetic properties; nanocomposites; nanomaterials; nanostructured materials.

\section{INTRODUCTION}

A large range of $\mathrm{Bi}$-substituted iron garnet (Bi:IG) compounds with compositions described by the generic formula $(\mathrm{Bi}, \mathrm{RE})_{3}(\mathrm{Fe}, \mathrm{M})_{5} \mathrm{O}_{12}$, where $\mathrm{RE}$ stands for a rare-earth atom and $\mathrm{M}$ is a metal atom like $\mathrm{Ga}$ or $\mathrm{Al}$, have been synthesized since the 1960s using various physical [1-7] and chemical [8-11] methods. Bi:IGs have initially found widespread application in magnetic recording technologies, after the discovery of giant Faraday effect in Bi:IG garnet materials in 1969 [3]. In recent decades, significant research attention had been devoted to the synthesis of highly Bi-substituted iron garnets by multiple groups working worldwide in diverse fields ranging from magnetic data recording to photon-

\footnotetext{
*Paper based on a presentation made at the International Conference on Nanomaterials and Nanotechnology (NANO-2010), Tiruchengode, India, 13-16 December 2010. Other presentations are published in this issue, pp. 1971-2113.

+Corresponding authors: E-mail: k.alameh@ecu.edu.au and m.nur-e-alam@ecu.edu.au
} 
ics and quantum-optical information processing [12-16]. Highly Bi:IG materials in which the Bi content approaches its theoretical maximum of 3 formula units are very promising for optics and photonics applications due to possessing record-high Faraday rotation which, in turn, allows control over the polarization states of the transmitted light signals on a nanosecond-range time scale. The optical, magnetic, and magneto-optical (MO) properties of all garnet materials depend significantly on the Bi substitution levels (within the dodecahedral sublattice of the garnet structure) as well as on all other substitution atoms and dopants content [2]. More recently, many new and exciting technologies which rely on using Bi:IG compounds have started to appear, ranging from the synthesis of magnetic-garnet nanoparticles [11] to the development of magnetic photonic crystals [16] for a wide range of applications. Various physical approaches including crystal growth from melts and from vapor phase (liquidphase epitaxy and vapor-phase epitaxy techniques) and physical vapor deposition techniques (such as radio-frequency, RF, magnetron sputtering and pulsed laser deposition) have made the growth of highquality, impurity-phase-free garnet-phase layers on various substrate types feasible [4-7]. In most cases, the use of physical vapor deposition techniques leads initially to growing the amorphous-phase oxide mixes (for all substrate temperatures during the deposition process below the crystallization temperature of any given garnet type), which do not possess any ferrimagnetic properties characteristic of Bi:IG. For high substrate temperatures (in excess of $500-600{ }^{\circ} \mathrm{C}$ ), the deposition processes can lead to growing the in situ crystallized or (most often) the partially crystallized (poly- or nanocrystalline) layers with the required garnet-type volume-averaged stoichiometry, which then still require suitably optimized post-deposition annealing processes for garnet phase formation. Finely optimized deposition processes using hot monocrystalline garnet substrates which are very closely lattice-matched to the growing garnet layers have led to obtaining epitaxial-quality garnet layer growth [20]. Despite the fact that all physical vapor deposition pathways toward the Bi:IG synthesis require complex and multiparameter process optimizations at both the deposition and annealing stages, this approach to garnet synthesis has the strongest potential for the practical use of this class of functional materials in photonic integrated circuits, optical fiber components, and other technologies linked to using microfabrication processes. We believe that RF sputtering deposition followed by the oven post-annealing in air atmosphere is the most flexible approach to MO garnet materials synthesis, which is also most compatible with other material types and with various modern microfabrication technologies. Most importantly, this approach allows the most efficient engineering of the garnet material properties through conveniently implementing the required variations in the chemical composition without having to redesign any principal synthesis pathways.

In this paper, we report on the synthesis of several important types of high-performance nanocrystalline ferrimagnetic garnet materials suitable for use in various photonics applications and also in MO imaging, as well as document a number of technological process details and parameters relevant to the synthesis of high-quality thin-film garnets. For the first time, we report on our estimates of the kinetics parameters of the crystallization processes relevant to the synthesis of MO garnet nanocomposites, which have recently been demonstrated to possess world-record MO figures of merit in the visible spectral range [7].

\section{FILM SYNTHESIS AND CHARACTERIZATION}

Multiple thin-film batches of Bi-substituted dysprosium-gallium iron garnet, Bi-substituted lutetiumaluminum iron garnet, and also several types of composite garnet- $\mathrm{Bi}_{2} \mathrm{O}_{3}$ films were prepared on glass (Corning 1737) and monocrystalline GGG (111)-oriented substrates by RF magnetron sputtering in low-pressure (1-2 mTorr) argon plasma under the process conditions specified in Table 1. The asdeposited films were amorphous and were later subjected to high-temperature oven annealing processes in air atmosphere to synthesize garnet-phase layers as a result of crystallization. As was expected, the optical and magnetic properties of the garnet materials synthesized depended significantly on their composition type and the degree of crystallization. The nanocomposite (co-sputtered) garnet-Bi-oxide lay- 
ers had a significantly improved optical transparency compared to the same garnet types deposited without co-sputtering $\mathrm{Bi}_{2} \mathrm{O}_{3}$, which is illustrated in Fig. 1.

Table 1 Typical RF sputtering deposition conditions and annealing process parameters used during the synthesis of high-quality MO garnet films.

\begin{tabular}{|c|c|}
\hline Process parameters & Values/comments \\
\hline Oxide-mix-based sputtering target stoichiometries & $\begin{array}{l}\mathrm{Bi}_{2} \mathrm{Dy}_{1} \mathrm{Fe}_{4} \mathrm{Ga}_{1} \mathrm{O}_{12}, \mathrm{Bi}_{2} \mathrm{Dy}_{1} \mathrm{Fe}_{4.3} \mathrm{Ga}_{0.7} \mathrm{O}_{12}, \\
\mathrm{Bi}_{1.8} \mathrm{Lu}_{1.2} \mathrm{Fe}_{3.6} \mathrm{Al}_{1.4} \mathrm{O}_{12}, \mathrm{Bi}_{2} \mathrm{O}_{3} \text { (AJA International, USA). } \\
\mathrm{Bi}_{2} \mathrm{O}_{3} \text { target was only used in two-source } \\
\text { co-sputtering processes. }\end{array}$ \\
\hline Sputter gas & $\mathrm{Ar}, \mathrm{P}($ total $)=1 \mathrm{mTorr}$. No oxygen input. \\
\hline Base pressure & $\mathrm{P}$ (base) $<1-2 \mathrm{E}-06$ Torr (high vacuum) \\
\hline RF power densities & $\begin{array}{l}3.3-7 \mathrm{~W} / \mathrm{cm}^{2}(150-320 \mathrm{~W}, 3 \text { " targets }) \text { - garnets; } \\
0.44-0.88 \mathrm{~W} / \mathrm{cm}^{2} \\
\left(20-40 \mathrm{~W}-\text { co-sputtered } \mathrm{Bi}_{2} \mathrm{O}_{3}\right)\end{array}$ \\
\hline Deposition rates & $\begin{array}{l}3.5-8.7 \mathrm{~nm} / \mathrm{min} \text { (garnets) } \\
1.2-5 \mathrm{~nm} / \mathrm{min}\left(\mathrm{Bi}_{2} \mathrm{O}_{3} \text { partial rates). }\right.\end{array}$ \\
\hline Substrate temperatures during deposition & $250^{\circ} \mathrm{C}$ (typ.) \\
\hline Substrate stage rotation rate $(\mathrm{rpm})$ & $30-40$ \\
\hline Target-to-substrate distance & $18 \pm 2 \mathrm{~cm}$ \\
\hline Sputtering system model and description & $\begin{array}{l}\text { KVS-T4065 (Korea Vacuum Technology, Ltd), } \\
\text { down-sputtering type, three RF guns for 3" targets. }\end{array}$ \\
\hline $\begin{array}{l}\text { Crystallization process temperatures and optimum } \\
\text { annealing duration (typical values) }\end{array}$ & $\begin{array}{l}1 \mathrm{~h} @ 700{ }^{\circ} \mathrm{C}\left(\mathrm{Bi}_{2} \mathrm{Dy}_{1} \mathrm{Fe}_{4} \mathrm{Ga}_{1} \mathrm{O}_{12} \text { and }\right. \\
\left.\mathrm{Bi}_{2} \mathrm{Dy}_{1} \mathrm{Fe}_{4.3} \mathrm{Ga}_{0.7} \mathrm{O}_{12}\right) \\
3 \mathrm{~h} @ 630^{\circ} \mathrm{C}\left(\mathrm{Bi}_{1.8} \mathrm{Lu}_{1.2} \mathrm{Fe}_{3.6} \mathrm{Al}_{1.4} \mathrm{O}_{12}\right) \\
30 \text { min @ } 580{ }^{\circ} \mathrm{C}^{\circ}\left(\mathrm{Bi}_{2} \mathrm{Dy}_{1} \mathrm{Fe}_{4} \mathrm{Ga}_{1} \mathrm{O}_{12}: \mathrm{Bi}_{2} \mathrm{O}_{3},\right. \\
\left.25 \text { vol \% excess } \mathrm{Bi}_{2} \mathrm{O}_{3}\right) ; \\
30 \text { min @ } 560{ }^{\circ} \mathrm{C}\left(\mathrm{Bi}_{2} \mathrm{Dy}_{1} \mathrm{Fe}_{4.3} \mathrm{Ga}_{0.7} \mathrm{O}_{12}: \mathrm{Bi}_{2} \mathrm{O}_{3},\right. \\
\left.17 \text { vol \% excess } \mathrm{Bi}_{2} \mathrm{O}_{3}\right) ; \\
10 \mathrm{~h} \mathrm{@610}{ }^{\circ} \mathrm{C}\left(\mathrm{Bi}_{1.8} \mathrm{Lu}_{1.2} \mathrm{Fe}_{3.6} \mathrm{Al}_{1.4} \mathrm{O}_{12}: \mathrm{Bi}_{2} \mathrm{O}_{3},\right. \\
\left.4.5 \text { vol \% excess } \mathrm{Bi}_{2} \mathrm{O}_{3}\right) ; \\
\text { Strongly composition-dependent annealing regimes for } \\
\text { all garnet-oxide composite formulations. }\end{array}$ \\
\hline
\end{tabular}
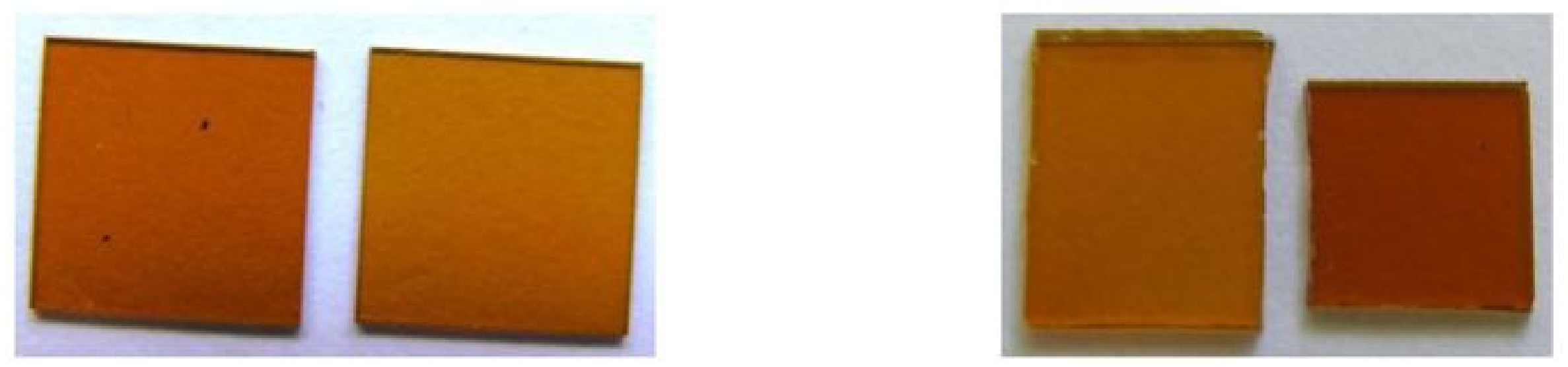

Fig. 1 (a) Left: 650-nm-thick film of $\mathrm{Bi}_{1.8} \mathrm{Lu}_{1.2} \mathrm{Fe}_{3.6} \mathrm{Al}_{1.4} \mathrm{O}_{12}$ on a $\mathrm{Gd}_{3} \mathrm{Ga}_{5} \mathrm{O}_{12}$ (GGG) substrate; Right: 1150-nm-thick film of $\left(\mathrm{Bi}_{1.8} \mathrm{Lu}_{1.2} \mathrm{Fe}_{3.6} \mathrm{Al}_{1.4} \mathrm{O}_{12}+20\right.$ vol \% co-sputtered $\left.\mathrm{Bi}_{2} \mathrm{O}_{3}\right)$ on a GGG substrate (both films are as-deposited); (b) Left: $1030 \mathrm{~nm}\left(\mathrm{Bi}_{2} \mathrm{Dy}_{1} \mathrm{Fe}_{4} \mathrm{Ga}_{1} \mathrm{O}_{12}: \mathrm{Bi}_{2} \mathrm{O}_{3} 24 \mathrm{vol} \%\right)$ on glass, after $2 \mathrm{~h} @ 580{ }^{\circ} \mathrm{C}$, Right: $1080 \mathrm{~nm} \mathrm{Bi}_{2} \mathrm{Dy}_{1} \mathrm{Fe}_{4.3} \mathrm{Ga}_{0.7} \mathrm{O}_{12}$ on $\mathrm{GGG}$, after $1 \mathrm{~h} @ 700{ }^{\circ} \mathrm{C}$. 
The optimum annealing regimes suitable for the crystallization of all garnet layers and (especially) the garnet- $\mathrm{Bi}_{2} \mathrm{O}_{3}$ composite films were found to be extremely composition-dependent. We experimentally optimized the annealing temperatures and process durations for the crystallization of a range of our garnet material types, in order to avoid the garnet decomposition processes and film surface degradation caused by the thermal over-exposure. The crystallized garnet material layers were characterized comprehensively using spectrophotometry, X-ray diffractometry (XRD), polarization microscopy, microstructure imaging, and MO testing.

The nominal stoichiometries of the sputtering targets $\mathrm{Bi}_{2} \mathrm{Dy}_{1} \mathrm{Fe}_{4.3} \mathrm{Ga}_{0.7} \mathrm{O}_{12}$ (oxide-mix-based) and $\mathrm{Bi}_{2} \mathrm{O}_{3}$ were used to deposit a large batch of composite garnet-oxide films of about $1100 \mathrm{~nm}$ thickness containing an estimated $(17 \pm 2)$ vol \% of added bismuth oxide, and the crystallization process kinetics of samples from this batch was studied in some detail for three different annealing temperatures $\left(550,560\right.$, and $\left.570{ }^{\circ} \mathrm{C}\right)$ to generate an estimate for the activation energy of the crystallization process. Multiple reports on the optical, magnetic, and MO properties of various MO garnet material types have been published to date, as well as some reports on the thermal processing techniques suitable for crystallizing Bi:IG films and also on the annealing behaviors of different MO garnet compounds [17-22]. Several studies have also been devoted in particular to the optimization of rapid thermal annealing regimes suitable for the crystallization of garnet films $[18,19]$. However, to the best of our knowledge, no reports have yet been published on the crystallization kinetics parameters of ovenannealed highly $\mathrm{Bi}$-substituted nanocomposite iron-garnet- $\mathrm{Bi}_{2} \mathrm{O}_{3}$ materials. The only report describing the crystallization kinetics and providing an estimate of the activation energy of crystallization for ovenannealed epitaxial garnet films could be found in [20]. We analyzed the time- and temperature dependencies of the extent of crystallization of our garnet-oxide materials and found these (as was expected) to satisfy the Avrami equation [23] and Arrhenius law for isothermal crystallization [24-26]. The activation energy of isothermal crystallization of our materials was found to be rather large (similarly to the results presented in [20]), which helps explain the substantial differences in the optimum annealing durations for processes run at different temperatures in this material type.

\section{RESULTS AND DISCUSSION}

Two important types of highly-Bi-substituted MO doped-iron-garnet compounds have been synthesized repeatably as high-quality thin films on optical substrates (Corning 1737 glass and polished monocrystalline $\mathrm{Gd}_{3} \mathrm{Ga}_{5} \mathrm{O}_{12}(\mathrm{GGG})$ ) and later characterized comprehensively. The first material type was described by the formula $(\mathrm{Bi}, \mathrm{Dy})_{3}(\mathrm{Fe}, \mathrm{Ga})_{5} \mathrm{O}_{12}$ and its nanocomposite derivatives of type $(\mathrm{Bi}, \mathrm{Dy})_{3}(\mathrm{Fe}, \mathrm{Ga})_{5} \mathrm{O}_{12}: \mathrm{Bi}_{2} \mathrm{O}_{3}$. We have previously reported on the optical and $\mathrm{MO}$ properties of this type of materials in [7]. The second material type tested was $(\mathrm{Bi}, \mathrm{Lu})_{3}(\mathrm{Fe}, \mathrm{Al})_{5} \mathrm{O}_{12}$ and its nanocomposite co-deposited derivatives $(\mathrm{Bi}, \mathrm{Lu})_{3}(\mathrm{Fe}, \mathrm{Al})_{5} \mathrm{O}_{12}: \mathrm{Bi}_{2} \mathrm{O}_{3}$. The two material types possessed similar optical properties and crystallization behavior, yet had very different magnetic and $\mathrm{MO}$ properties. To the best of our knowledge, the synthesis of garnet materials of the second type with high Bi content using any physical vapor deposition methods have not yet been reported in the literature.

\section{Bi-substituted Ga-doped dysprosium iron garnets}

$\mathrm{Bi}_{2} \mathrm{Dy}_{1} \mathrm{Fe}_{4} \mathrm{Ga}_{1} \mathrm{O}_{12}$ and $(\mathrm{BiDy})_{3}(\mathrm{FeGa})_{5} \mathrm{O}_{12}: \mathrm{Bi}_{2} \mathrm{O}_{3}$ layers synthesized on glass substrates have been studied using $\mathrm{X}$-ray diffraction analysis and microstructure imaging (transmission electron microscopy, TEM). The diffraction datasets obtained with Panalytical XPert Pro X-ray diffractometer configured for near-grazing-incidence measurements using $\mathrm{CuK} \alpha_{1}$ line $(\lambda=0.15406 \mathrm{~nm})$ are shown in Fig. 2, together with a cross-section microstructure image of a garnet layer obtained using high-resolution TEM. The diffraction patterns obtained showed peaks at a set of angles characteristic of the body-centered cubic lattice of garnets. Interestingly, the only impurity phase detected reliably was iron oxide $\mathrm{Fe}_{3} \mathrm{O}_{4}$ (identified through a search of the standard JCPDS XRD database limited by all chemical elements possibly 

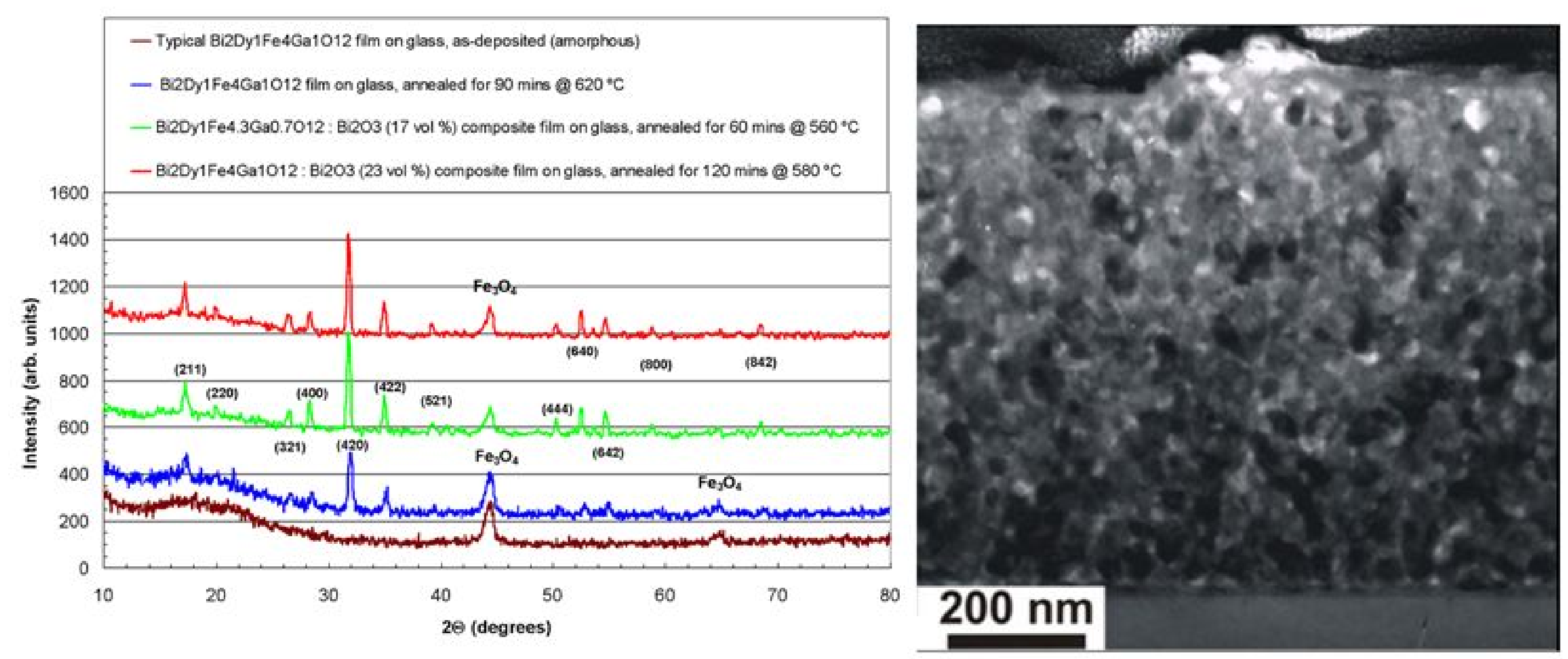

Fig. 2 (a) XRD datasets obtained from several types of sputtered thin-film garnet materials synthesized on glass substrates. In the inset, the XRD traces are described starting from the bottom trace upwards; (b) A cross-section microstructure image (TEM) of a crystallized $\mathrm{Bi}_{2} \mathrm{Dy}_{1} \mathrm{Fe}_{4} \mathrm{Ga}_{1} \mathrm{O}_{12}$ layer on a GGG substrate (image is courtesy of Electron Microscope Unit, the University of New South Wales, Sydney, Australia).

present in the film structure). The source of excess $\mathrm{Fe}_{3} \mathrm{O}_{4}$ was the sputtering target of stoichiometry $\mathrm{Bi}_{2} \mathrm{Dy}_{1} \mathrm{Fe}_{4} \mathrm{Ga}_{1} \mathrm{O}_{12}$ sintered from a mix of oxides, and all samples tested (as-deposited and crystallized) showed XRD peaks at angles $(2 \Theta)$ near $44.5^{\circ}$ and $65^{\circ}$. The diffraction datasets of the films synthesized by co-sputtering deposition with $\mathrm{Bi}_{2} \mathrm{O}_{3}$ showed significantly reduced iron-oxide peak intensities, suggesting that less iron oxide was present outside garnet nanocrystallites. $\mathrm{Bi}_{2} \mathrm{O}_{3}$ still remained in its amorphous phase after annealing and therefore did not generate any diffraction peaks.

The optical properties of $\mathrm{Bi}_{2} \mathrm{Dy}_{1} \mathrm{Fe}_{4} \mathrm{Ga}_{1} \mathrm{O}_{12}$ and (BiDy) ${ }_{3}(\mathrm{FeGa})_{5} \mathrm{O}_{12}: \mathrm{Bi}_{2} \mathrm{O}_{3}$ films as well as the oven-annealing regimes found suitable for the crystallization of this type of garnets have been reported in detail in [7].

\section{Bi-substituted Al-doped lutetium iron garnets}

Our motivation for the synthesis of $(\mathrm{Bi}, \mathrm{Lu})_{3}(\mathrm{Fe}, \mathrm{Al})_{5} \mathrm{O}_{12}$ films on optical substrates (glass and GGG) has been to establish the technology for the manufacture of magnetically soft garnet layers with high $\mathrm{Bi}$ substitution, magnetization vector direction close to being in the film's plane, and possessing high MO figures of merit in the visible and near-infrared ranges. The latter figure is defined as the doubled ratio of the specific Faraday rotation to the absorption coefficient at any given wavelength $\left(Q=2 \Theta_{\mathrm{F}} / \mathrm{A}\right)$ and determines the suitability of $\mathrm{MO}$ materials for most practical applications. $(\mathrm{Bi}, \mathrm{Lu})_{3}(\mathrm{Fe}, \mathrm{Al})_{5} \mathrm{O}_{12}$ films have only been synthesized previously by using liquid-phase epitaxy, but that technique does not allow synthesis of garnet films with high Bi substitution (approaching 2.0 formula units and above). We selected a sputtering target of stoichiometry $\mathrm{Bi}_{1.8} \mathrm{Lu}_{1.2} \mathrm{Fe}_{3.6} \mathrm{Al}_{1.4} \mathrm{O}_{12}$ as deposition material source and deposited several batches of garnet and also garnet- $\mathrm{Bi}_{2} \mathrm{O}_{3}$ films using essentially the same deposition process parameters as for $\mathrm{Bi}$-substituted dysprosium iron garnets. The result was the development of new thin-film garnet material with optical and MO properties useful for a range of applications in MO sensors and magnetic field imagers and possessing very high $\mathrm{MO}$ figure of merit. As was expected, the synthesis of co-deposited nanocomposites of type $(\mathrm{Bi}, \mathrm{Lu})_{3}(\mathrm{Fe}, \mathrm{Al})_{5} \mathrm{O}_{12}: \mathrm{Bi}_{2} \mathrm{O}_{3}$ has led to films with improved optical transparency and therefore with better MO quality. The effect of excess $\mathrm{Bi}_{2} \mathrm{O}_{3}$ concentration on the magnetic properties of these materials is currently under investigation. The initial results of the optical, magnetic, and MO characterization of this type of MO films are presented in Figs. 3 and 4. 

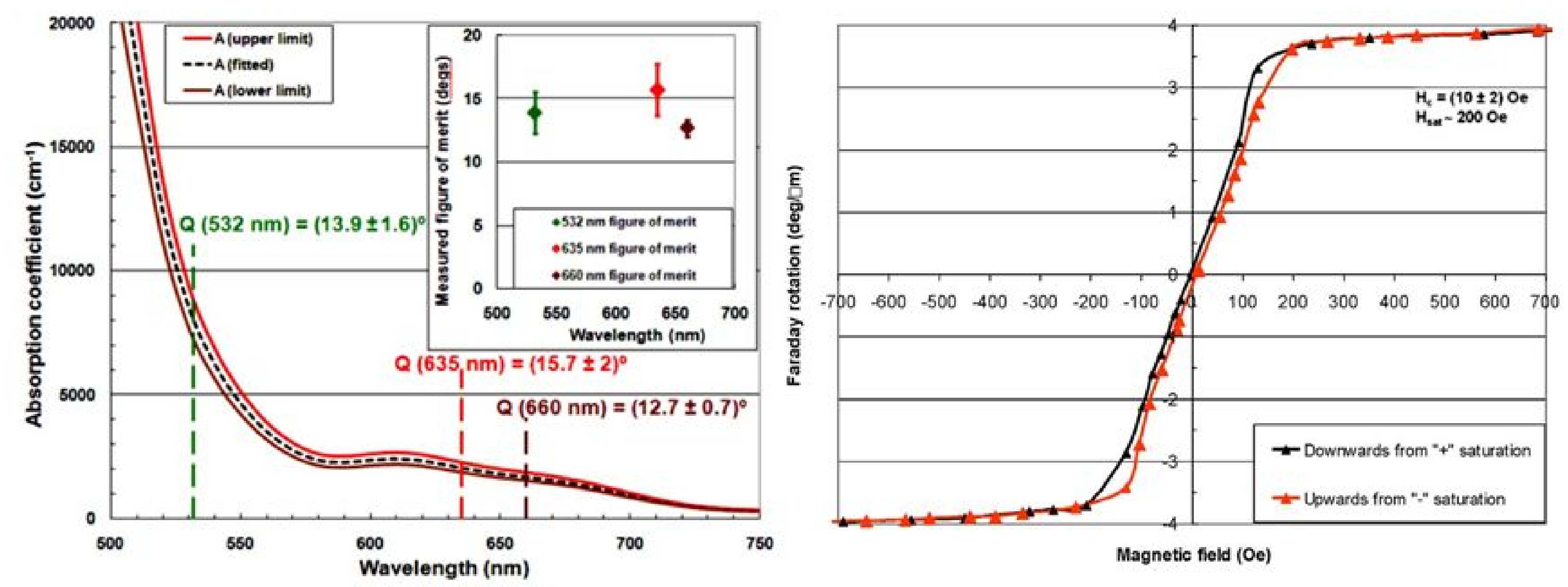

Fig. 3 (a) Derived absorption coefficient spectrum showing the upper (red color) and lower limits (brown color) of $\mathrm{Bi}_{1.8} \mathrm{Lu}_{1.2} \mathrm{Fe}_{3.6} \mathrm{Al}_{1.4} \mathrm{O}_{12}$ garnet films deposited onto GGG (111) substrates and annealed at $650{ }^{\circ} \mathrm{C}$ for $1 \mathrm{~h}$. The data points for the MO figure of merit measured at 532, 635, and $660 \mathrm{~nm}$ with their associated error bars are shown in the inset; (b) Hysteresis loop of specific Faraday rotation measured at $532 \mathrm{~nm}$ in sputtered $\mathrm{Bi}_{1.8} \mathrm{Lu}_{1.2} \mathrm{Fe}_{3.6} \mathrm{Al}_{1.4} \mathrm{O}_{12}$ garnet films of $650 \mathrm{~nm}$ thickness deposited onto GGG substrates at $680^{\circ} \mathrm{C}$ substrate temperature and annealed for $3 \mathrm{~h}$ at $630^{\circ} \mathrm{C}$.
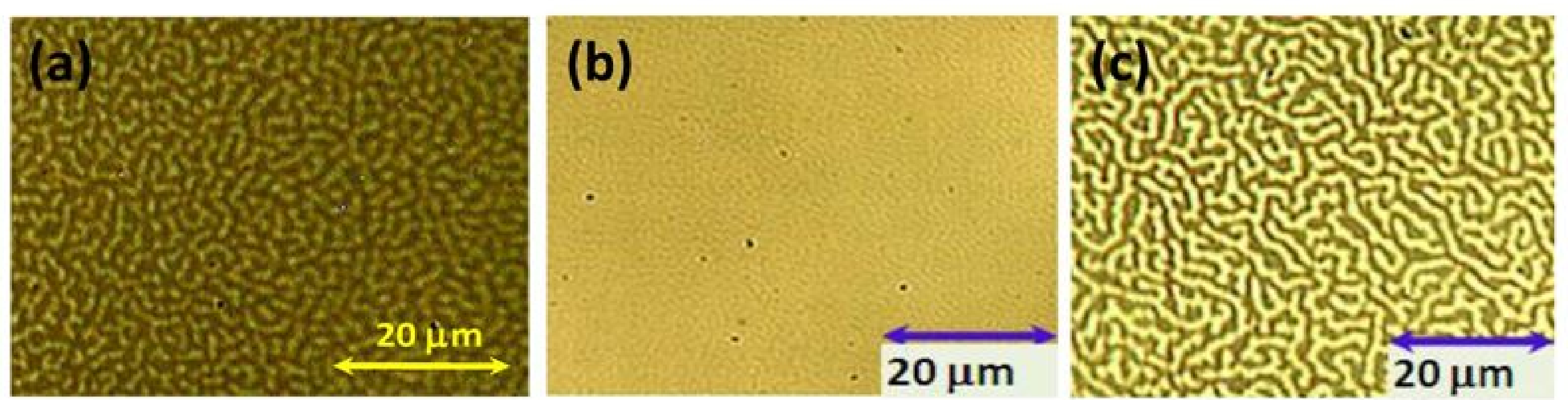

Fig. 4 Regular maze-type magnetic domain patterns observed in sputtered and later oven-crystallized $\mathrm{Bi}_{1.8} \mathrm{Lu}_{1.2} \mathrm{Fe}_{3.6} \mathrm{Al}_{1.4} \mathrm{O}_{12}$ garnet films on GGG substrates deposited at (a) $250{ }^{\circ} \mathrm{C} \mathrm{T}$ (sub) (annealed for $1 \mathrm{~h}$ @ $650{ }^{\circ} \mathrm{C}$ ); (b) $680{ }^{\circ} \mathrm{C} \mathrm{T}$ (sub) (annealed for $3 \mathrm{~h} @ 630{ }^{\circ} \mathrm{C}$ ) and (c) $\mathrm{Bi}_{1.8} \mathrm{Lu}_{1.2} \mathrm{Fe}_{3.6} \mathrm{Al}_{1.4} \mathrm{O}_{12}: \mathrm{Bi}_{2} \mathrm{O}_{3}(4.5$ vol \%) composite garnet films (deposited at $250{ }^{\circ} \mathrm{C}$ and annealed for $10 \mathrm{~h} @ 610^{\circ} \mathrm{C}$ ). The images were obtained using a transmission-mode polarization microscope at high magnification.

\section{Kinetics of garnet nanocrystals formation within the garnet- $\mathrm{Bi}_{2} \mathrm{O}_{3}$ nanocomposites}

Our analysis of the annealing behavior of garnet-oxide composites was limited to the conventional oven-annealing processes, in which isothermal crystallization was achieved at the "annealing temperatures" as specified, and the temperature-ramp processes were run at a constant rate of $5{ }^{\circ} \mathrm{C} / \mathrm{min}$. Since we estimated the absolute accuracy of temperature control achievable in our oven to be about $\pm 5^{\circ} \mathrm{C}$, we defined the "annealing process duration" in our analysis to be equal to the duration of the isothermal crystallization process plus two minutes, in order to account for the effects of the last minute of the temperature ramp-up process and the first minute of the temperature ramp-down process. We performed a series of annealing experiments with a large batch of garnet-oxide nanocomposite films of composition type $\mathrm{Bi}_{2} \mathrm{Dy}_{1} \mathrm{Fe}_{4.3} \mathrm{Ga}_{0.7} \mathrm{O}_{12}: \mathrm{Bi}_{2} \mathrm{O}_{3}(17 \mathrm{vol} \%$ ) using a conventional box-furnace-type oven system (Sentrotech, Inc., USA) at the process temperatures of 550,560 , and $570{ }^{\circ} \mathrm{C}$, for a number of different annealing durations, and studied the evolution of the optical and MO properties to characterize the garnet crystallization kinetics of this material. We observed significantly shorter optimum annealing dura- 
tions which led to maximized specific Faraday rotation (about 4-6 min) for processes run at $570{ }^{\circ} \mathrm{C}$ compared to these run at $550{ }^{\circ} \mathrm{C}$ (about $45-60 \mathrm{~min}$ ).

The amorphous (as-deposited) to nanocrystalline phase transformation kinetics was studied using the samples with high-quality surfaces (except in some over-annealed films), and possessing good optical and MO properties. Since the conventional oven-annealing processes induce the temperature-activated crystallization of amorphous (as-deposited) garnet layers, it is of interest to quantify the activation energy of these crystallization processes. We followed the approach described in [23-26] for this analysis. It is well known that the kinetics of thermally activated processes (including the case of garnet crystallization being considered) follows a dependence on temperature described by the Arrhenius law (eq. 1)

$$
K=K_{0} \cdot \exp \left(-\frac{E_{\mathrm{c}}}{k T}\right)
$$

where $K$ is the rate constant of the crystallization process, $K_{0}$ is termed the pre-exponential factor, $E_{\mathrm{c}}$ is the activation energy of crystallization, and $k$ is the Boltzmann constant. During the isothermal phase change, the extent of crystallization $A$ of a material is described by Avrami's equation (eq. 2) [23]

$$
A(t)=1-e^{(-K \cdot t)^{n}}
$$

where $t$ is the process duration and $n$ is the order parameter dependent on the crystal growth mechanism.

The extent of crystallization was quantified as the ratio of the specific Faraday rotation measured in films after running any given annealing process, to the maximum specific Faraday rotation at the same wavelength (we used 532- and 635-nm light) achieved in any given material/substrate system after running the process at the same annealing temperature with the "best-known" parameters. All specific Faraday rotation data obtained from film samples deposited onto GGG substrates and possessing rectangular hysteresis loops were measured in their remnant magnetization states, in order to exclude the paramagnetic effects of 0.5 -mm-thick GGG substrates which led to measuring slightly increased Faraday rotation angles when placed in the electromagnet's field of up to $2.5 \mathrm{kOe}$. For samples deposited onto Corning 1737 glass substrates, Faraday rotation data was taken at the saturation magnetization, even though all films maintained about $90 \%$ of Faraday rotation after being removed from the electromagnet. The data analysis strategy used to derive the Arrhenius equation parameters of our garnet materials followed the approach reported in [24-26].

Figure 5 illustrates a typical relationship between the measured extent of crystallization and the annealing time (a sigmoid-shaped crystallization curve) and some data used to derive the estimate for the activation energy. It is important to note that some data points in the dependencies of the extent of crystallization on process duration were considered "outliers" since these were observed outside the expected linear trends in the logarithmic plot used for linear regression fitting. The latter was likely due to the variations in the phase content of film samples (the presence of some residual iron oxide and also variations in excess vol \% of $\mathrm{Bi}_{2} \mathrm{O}_{3}$ ).

Avrami plots of $\ln [\ln (1 /(1-A))]$ vs. $\ln (t)$ were studied to reveal the values of crystallization order parameters and also these of $\ln (K)$. The "outlier" or "over-annealed" data points not used in the regression fitting are also shown within dashed circles. All time durations were measured in minutes. The slopes and the intercepts of the plots of $\ln [\ln (1 /(1-A))]$ vs. $\ln (t)$ as shown in Fig. 5b revealed the (approximate) values of the crystallization order parameter and also these of $\ln (K)$ at each process temperature. According to the Arrhenius expression (eq. 1), the crystallization rate constant is a function of temperature, and it is well known that it also depends on both the nucleation and growth rates of the new phase. Annealing at higher temperatures increases the growth rate substantially, but studies of crystallization at temperatures above $570{ }^{\circ} \mathrm{C}$ could not be carried out due to the oven temperature con- 

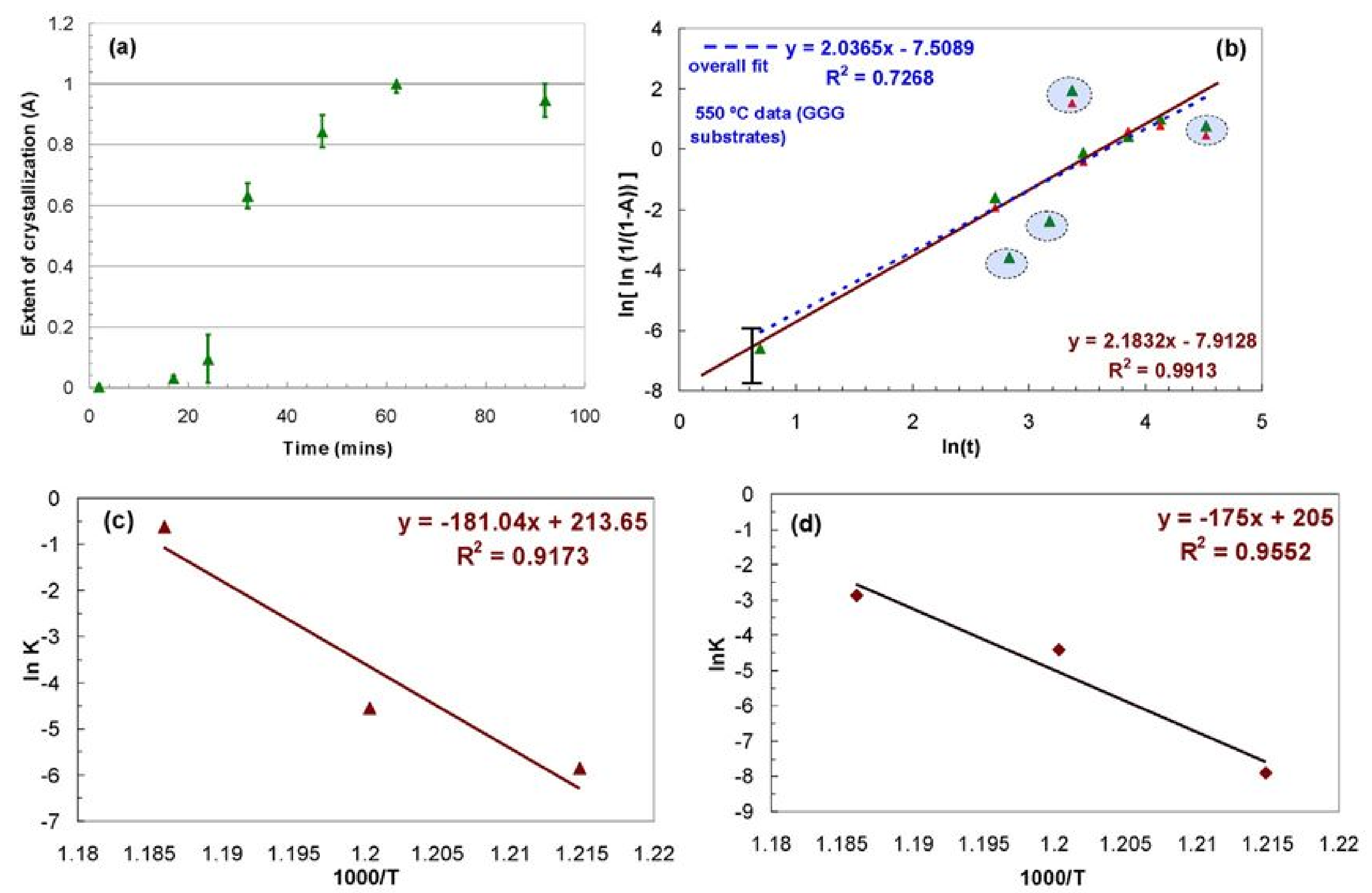

Fig. 5 (a) Relationship between the extent of crystallization (A) and the annealing time (isothermal crystallization process duration) for garnet-oxide composite films of type $\mathrm{Bi}_{2} \mathrm{Dy}_{1} \mathrm{Fe}_{4.3} \mathrm{Ga}_{0.7} \mathrm{O}_{12}: \mathrm{Bi}_{2} \mathrm{O}_{3}(17 \pm 2$ vol \%) deposited onto GGG substrates and annealed for different time durations at $550^{\circ} \mathrm{C}$; (b) plot of $\ln [\ln (1 /(1-A))]$ vs. $\ln (t)$ for the films of same composition annealed at $550^{\circ} \mathrm{C}$, some data points which were considered "outliers" are shown within dashed circles; (c, d) Arrhenius plots of $\ln (K)$ vs. $1000 / T$ for $\mathrm{Bi}_{2} \mathrm{Dy}_{1} \mathrm{Fe}_{4.3} \mathrm{Ga}_{0.7} \mathrm{O}_{12}: \mathrm{Bi}_{2} \mathrm{O}_{3}(17 \pm 2$ vol \%) composite films sputtered onto (c) Corning 1737 glass and (d) GGG (111) substrates.

troller's limitations. On the other hand, annealing at low temperatures (in our case, below $550{ }^{\circ} \mathrm{C}$ ) was not productive due to the very slow crystallization rates, which could mean that weeks or even years of annealing would be required to transform the amorphous-phase materials into polycrystalline phase.

For thermally activated isothermal crystallization processes, the Arrhenius equation shows that the crystallization rate constant is significantly temperature-dependent, and the obtained linear-regression straight-line fits of the $\ln (K)$ vs. $1000 / T$ data points confirm the applicability of Arrhenius law to the process considered. The slopes of fitted lines shown in the Arrhenius plots of Figs. $5 \mathrm{c}, \mathrm{d}$ are defined by the activation energy of crystallization, whilst the intercepts can be used to reveal the value of the pre-exponential factor of the crystallization process $\left(\ln \left(K_{o}\right)\right)$. Only three temperature data points were used due to the narrowness of the thermal processing window suitable for the material type selected, and because we utilized only (a limited number of) material samples from a single deposition batch. Therefore, any material composition uncertainties arising out of batch-to-batch repeatability were excluded. Using eq. 1 and the fitted regression slope values shown in Figs. $5 \mathrm{c}$,d, the following estimates of the activation energy of garnet nanocrystals formation were obtained: $14.99 \mathrm{eV}$ for films deposited onto GGG substrates and $15.6 \mathrm{eV}$ for films deposited onto Corning 1737 glass substrates; both values were estimated to about $\pm 10 \%$ accuracy. It is important to note that the activation energy values obtained from our estimates were much larger than those expected for simple diffusion-driven processes. This might indicate that diffusion and also nucleation/growth mechanisms as well as inter- 
face processes may affect the overall kinetics of the rather complex crystallization process, as described by the authors of [26].

The optimization of annealing regimes used for this material type $\left(\mathrm{Bi}_{2} \mathrm{Dy}_{1} \mathrm{Fe}_{4.3} \mathrm{Ga}_{0.7} \mathrm{O}_{12}\right.$ co-sputtered with est. (17 \pm 2$) \%$ of excess bismuth oxide coming from a different target) enabled some improvement in the MO figures of merit (as measured in the visible range) compared with the results previously achieved for this material type and published in [7]. The chemical composition, crystal structure, and the microstructural properties of our range of garnet-oxide nanocomposite films annealed using different regimes are being investigated and will be reported elsewhere.

\section{CONCLUSION}

We have studied the synthesis of several important types of Bi:IG compounds using RF sputtering deposition technology and high-temperature post-deposition annealing. The properties of $\mathrm{MO}$ garnet thin films of composition types $(\mathrm{BiDy})_{3}(\mathrm{FeGa})_{5} \mathrm{O}_{12},(\mathrm{BiLu})_{3}(\mathrm{FeAl})_{5} \mathrm{O}_{12},(\mathrm{BiDy})_{3}(\mathrm{FeGa})_{5} \mathrm{O}_{12}: \mathrm{Bi}_{2} \mathrm{O}_{3}$, and $(\mathrm{BiLu})_{3}(\mathrm{FeAl})_{5} \mathrm{O}_{12}: \mathrm{Bi}_{2} \mathrm{O}_{3}$ have been discussed. We have shown that these materials can possess very high $\mathrm{MO}$ performance, nanocrystalline densely packed microstructure with very fine grains, and very attractive magnetic properties, making them useful for diverse applications in nanophotonics, ultrafast optical devices, and integrated optoelectronics. A study of crystallization kinetics undertaken with a sample batch of garnet- $\mathrm{Bi}_{2} \mathrm{O}_{3}$ composite films has yielded the estimates of the activation energy of isothermal crystallization for this type of material. The results presented can be used as a guide for obtaining high-performance garnet films and for the design of optimized thermal processing regimes suitable for the synthesis of highly Bi-substituted garnets using physical vapor deposition methods.

\section{ACKNOWLEDGMENTS}

This research is supported by the Faculty of Computing, Health and Science, Edith Cowan University. We also acknowledge the support provided by the Department of Nanobio Materials and Electronics, Gwangju Institute of Science and Technology (Republic of Korea).

\section{REFERENCES}

1. G. B. Scott, D. E. Lacklison. IEEE Trans. Magn. 12, 292 (1976).

2. A. K. Zvezdin, V. A. Kotov. In: Modern Magnetooptics and Magnetooptical Materials, Institute of Physics Publishing, Bristol and Philadelphia (1997).

3. C. F. Buhrer. J. Appl. Phys, 40, 4500 (1969).

4. T. Okuda, N. Koshizuka, K. Hayashi, T. Takahashi, H. Kotani, H. Yamamoto. Advances in Magneto-Optics, Proc. Int. Symp. Magneto-Optics, J. Magn. Soc. Jpn. 11, Supplement S1, 179 (1987).

5. Y. H. Kim, J. S. Kim, S. I. Kim, M. Levy. J. Korean Phys. Soc. 43, 400 (2003).

6. S.-H. Wee, H.-S. Hong, Y.-H. Kim, S.-I. Yoo, J. Kang. Metals Mater. Int. 9, 507 (2003).

7. M. Vasiliev, M. Nur-E-Alam, V. A. Kotov, K. Alameh, V. I. Belotelov, V. I. Burkov, A. K. Zvezdin. Opt. Express 17, 19519 (2009).

8. X. Ma, S. Zhang, F. Li, D. Que. J. Mater. Sci.: Mater. Electron. 9, 347 (1998).

9. N. Dubnikova, E. Garskaite, J. Pinkas, P. Bezdicka, A. Beganskiene, A. Kareiva. J. Sol-Gel Sci. Technol. 55, 213 (2010).

10. Y. Zhang, X. Wang, H. Xia, D. Shen, F. Gan, S. Wang. J. Mater. Sci. Technol. 20, 66 (2004).

11. T. Kim, S. Nasu, M. Shima. J. Nanoparticle Res. 9, 737 (2007).

12. K. Nakagawa, S. Kurashina, A. Itoh. J. Appl. Phys. 75, 7096 (1994).

13. S. Kang, S. Yin, V. Adyam, Q. Li, Y. Zhu. IEEE Trans. Magn. 43, 3656 (2007).

14. M. Nur-E-Alam, M. Vasiliev, K. Alameh. Opt. Quant. Electron. 41, 661 (2010).

(C) 2011, IUPAC

Pure Appl. Chem., Vol. 83, No. 11, pp. 1971-1980, 2011 
15. A. Abdelrahman, M. Vasiliev, K. Alameh, P. Hannaford. Phys. Rev. A 82, 012320 (2010).

16. I. L. Lyubchanskii, N. N. Dadoenkova, M. I. Lyubchanskii, E. A. Shapovalov, Th. Rasing. J. Phys. D: Appl. Phys. 36, R277 (2003).

17. W. T. Stacy, M. A. H. Huyberts, R. Metselaar, A. B. Voermans. J. Appl. Phys. 48, 4766 (1977).

18. T. Suzuki, G. Zaharchuk, G. Gorman, F. Sequeda, P. Labun. IEEE Trans. Magn. 26, 1927 (1990).

19. T. Suzuki. J. Appl. Phys. 69, 4756 (1991).

20. F. B. Hagedorn. J. Appl. Phys. 45, 3123 (1974).

21. A. Sztaniszlav, M. Farkas-Jahnke, M. Balla. J. Magn. Magn. Mater. 215-216, 188 (2000).

22. Q. Yang, Z. Huaiwu, L. Yingli, W. Qiye. IEEE Trans. Magn. 43, 3652 (2007).

23. M. Avrami. J. Chem. Phys. 8, 212 (1940).

24. N. Mehta, A. Kumar. J. Mater Sci. 42, 490 (2007).

25. G. H. Adel, A. S. Abdrabo. J. Ovonic Res. 5, 51 (2009).

26. R. P. Mathur, D. Akhtar. Bull. Mater. Sci. 9, 267 (1987). 